\title{
An economic analysis of the costs associated with weight status in chronic obstructive pulmonary disease (COPD)
}

\author{
P. F. Collins, R. J. Stratton and M. Elia \\ Institute of Human Nutrition, School of Medicine, University of Southampton, Southampton, SO16 6YD, UK
}

\begin{abstract}
Malnutrition in patients with COPD is a common problem which has been associated with increased healthcare utilisation ${ }^{(1)}$. In contrast, epidemiological studies have reported that obesity in COPD is associated with better survival than both underweight and normal weight COPD patients ${ }^{(2)}$, contributing to the concept of the 'obesity paradox', The aim of this study is to examine the extent to which weight status, over a wide range of body mass index (BMI), influences healthcare costs in COPD.

424 outpatients with COPD were followed up for 1 year post screening during 2008-2009. BMI and healthcare use (emergency and elective hospital admissions, length of stay, outpatient appointments) were recorded. Healthcare costs were established according to Department of Health NHS reference costs $2007^{(3)}$ and modelled according to BMI classification at the point of screening.
\end{abstract}

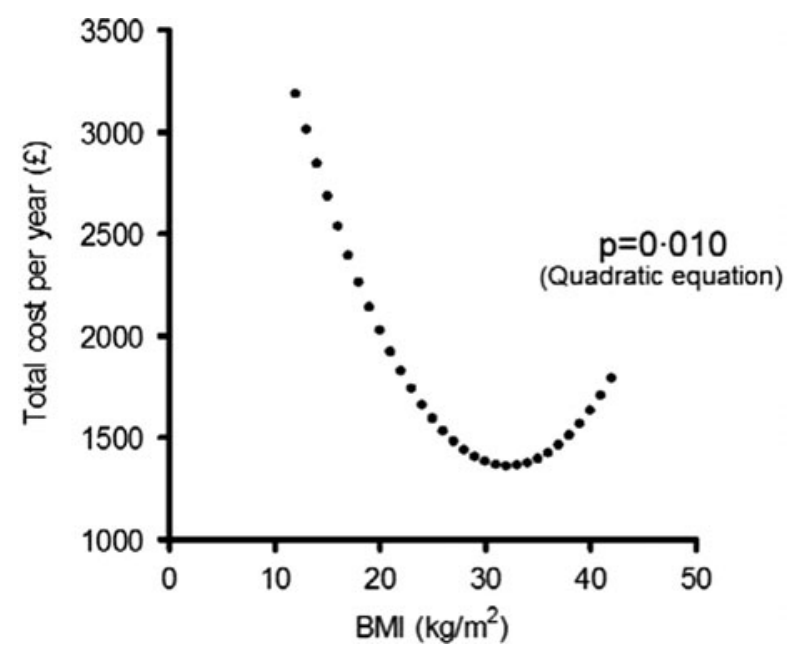

Fig. 1. Total secondary healthcare use costs per patient per year according to BMI, adjusted for age, gender and COPD disease-severity (GOLD 2009), using univariate analysis.

The figure shows that the lowest healthcare costs are associated with a BMI in the obesity range (BMI $\sim 32 \mathrm{~kg} / \mathrm{m}^{2}$ ), an increase in the BMI range of $20-25 \mathrm{~kg} / \mathrm{m}^{2}$ and as much as a 2 to 3 -fold increase in the BMI range of $<20 \mathrm{~kg} / \mathrm{m}^{2}$. The increased costs associated with a BMI $<25 \mathrm{~kg} / \mathrm{m}^{2}$ were mainly attributed to increased frequency of emergency admissions. The costs increased in the severely obese $\left(\mathrm{BMI}>40 \mathrm{~kg} / \mathrm{m}^{2}\right)$ but were not as high as those who were underweight $\left(\mathrm{BMI}<20 \mathrm{~kg} / \mathrm{m}^{2}\right)$.

This study suggests that after adjusting for certain confounding variables including COPD severity (Fig. 1) the lowest costs were associated with obesity (BMI $30-35 \mathrm{~kg} / \mathrm{m}^{2}$ ) and the highest with underweight $\left(\mathrm{BMI}<20 \mathrm{~kg} / \mathrm{m}^{2}\right)$. The optimal BMI for nutritional intervention in COPD remains to be established.

Acknowledgement: funded by an unrestricted educational grant from Nutricia Ltd.

1. Collins PF, Stratton RJ, Kurukulaaratchy R \& Elia M (2010) Thorax 65, A73-A74.

2. Vestbo J, Prescott E, Almdal T, Dahl M, Nordestgaard BG, Andersen T, Sorensen TI \& Lange P (2006) Am J Respir Crit Care Med 173, 79-83.

3. Department of Health (2007) NHS reference costs 2007. www.doh.gov.uk 